\title{
A randomized clinical trial of different associations between dexamethasone and non-steroids anti- inflammatories in the lower third molar extractions
}

\section{Gustavo Antonio Correa Momesso}

Sao Paulo State University

Gustavo Augusto Grossi Oliveira

Sao Paulo State University

William Phillip Pereira Silva

Sao Paulo State University

Renan Akira

Sao Paulo State University

\section{Fernando Chiba}

Sao Paulo State University

\section{Tárik Ocon Braga Polo}

Sao Paulo State University

Tiburtino José Lima Neto

Sao Paulo State University

Bárbara Ribeiro Rios

Sao Paulo State University

Ana Paula Farnezi Bassi

Sao Paulo State University

Doris Hissako Sumida

Sao Paulo State University

Michael Han

University of Illinois at Chicago

Michael Miloro

University of Illinois at Chicago

Leonardo Perez Faverani ( $\sim$ leonardo.faverani@unesp.br)

Sao Paulo State University

\section{Research Article}

Keywords: third molar, edema, analgesia, prostaglandin E2 
Posted Date: March 25th, 2021

DOI: https://doi.org/10.21203/rs.3.rs-224127/v1

License: (c) (i) This work is licensed under a Creative Commons Attribution 4.0 International License. Read Full License 


\section{Abstract}

Objectives The aim of this study is to evaluate the preemptive analgesic effects of dexamethasone (DEX) alone or combined with non-steroidal anti-inflammatory drugs (NSAIDs) in third molar surgeries.

Materials and Methods The subjects were divided into five groups ( $\mathrm{n}=20$ teeth/group); subjects received only $8 \mathrm{mg}$ of dexamethasone 1 hour before the surgical procedure (DEX group), or in combination with etodolac (DEX + ETO), ketorolac (DEX + KET), ibuprofen (DEX + IBU), loxoprofen (DEX + LOX). Paracetamol $750 \mathrm{mg}$ was provided as the number of rescue analgesics (NRA). Salivary PGE2 expression was measured preoperatively and at 48 hours. Edema and Maximum mouth opening (MMO) were measured postoperatively at $48 \mathrm{~h}$ and 7 days. A visual analog scale (VAS) was performed postoperatively at 6,12 , $24,48,72$ hours, and 7 days.

Results Salivary expression of PGE2 showed a decrease only for the DEX group. Edema and MMO and NRA consumption showed no significant differences among the groups $(P>0.05)$. The VAS showed a significantly lower pain perception at 6 hours after the surgery for the DEX + ETO and DEX + KET groups $(P<0.05)$.

Conclusions The combination of DEX and NSAIDS should be considered for preemptive acute postsurgical pain management in third molar surgery. Clinical Relevance: In some drug associations such as dexamethasone $8 \mathrm{mg}+$ NSAIDS (ETO and KET), and others, the isolated administration of a single dose of dexamethasone in the pre-operative time, only a few rescue analgesics are necessary.

\section{Introduction}

Postoperative pain and edema remain significant concerns for patients who undergo third molar removal. For this reason, the literature contains several studies about controlling these symptoms. ${ }^{[1]}$ It is the responsibility of the surgeon to treat the postoperative symptoms of challenging third molar surgeries, which can be quite intense, limiting patients' daily routines, and causing considerable discomfort. $[2,3]$

Thus, preoperative drug therapies have been suggested to prevent or relieve postoperative symptoms. ${ }^{[2,4]}$ Preemptive analgesia consists of managing drugs prior to nociceptive stimulation and is defined as an anti-nociceptive treatment that prevents the inflammatory response from stimulation of the afferent pathway to the central nervous system. This general mechanism is responsible for the amplification of the postoperative pain response. ${ }^{[5]}$

Steroidal anti-inflammatory drugs (e.g. corticosteroids) are used extensively during the preoperative period prior to third molar surgery. Several authors have demonstrated the efficacy of these drugs, mainly in the control of postoperative edema and trismus (MMO). ${ }^{[6-8]}$ This effect is achieved because corticosteroids inhibit the conversion of phospholipids into arachidonic acid by phospholipase A2. This mechanism is responsible for preventing the production of leukotrienes, prostacyclins, prostaglandins, 
and thromboxane A2, which mediate pain and inflammation. The use of corticosteroids is believed to inhibit the initial step in this process. ${ }^{[9]}$

Nonsteroidal anti-inflammatory drugs (NSAIDs) are mostly used during the postoperative period of third molar surgeries due to their considerable anti-nociceptive effects. ${ }^{[10-12]}$ However, recent studies have demonstrated that the preemptive combination of NSAIDs and corticosteroids seems to improve the relief

of postoperative symptoms after third molar surgeries, mainly in the acute postoperative period. ${ }^{[4,13,14]} \mathrm{A}$ possible explanation for the efficacy of this combination is that when administered before surgical trauma and the onset of pain, the drugs will be present in the bloodstream at the appropriate levels, and at the appropriate time when pain symptoms begin, and the inhibition of cyclooxygenase decreases the production of prostaglandins and other inflammatory cytokines at the surgical site. ${ }^{[15]}$

Since there is a lack of consensus and few studies regarding the preemptive combination of steroids and NSAIDs aimed at improving the postoperative pain symptoms after third molar surgery, the purpose of this study is to compare the preemptive use of dexamethasone alone, and the combination of dexamethasone with different NSAIDs, in third molar surgeries.

\section{Methods}

\section{Ethical Considerations}

This prospective, randomized, triple-blind clinical trial was approved by the Ethical Committee for Human Experimentation from the São Paulo State University - School of Dentistry, Araçatuba - São Paulo, Brazil (number \# 88903518.4.0000.5420). The trial was registered in a Brazilian Clinical Trials Registry (REBEC date of registration: 14/02/2019 - number of registration: \#RBR-8rfwnq) and was written in accordance with the CONSORT guidelines (www.consort-statement.org) and the principles for medical research involving human subjects in the 1963 Declaration of Helsinki [16]. All subjects received the research information through the informed consent process. The patients were initially informed that the research aimed to compare many different drugs usually used in relieving the inflammatory symptoms and pain, and they were not aware about what the drugs were prescribed for. Besides that, all the risks about the surgical procedure were informed such as local and systemic infections, alveolar inferior nerve and lingual paresthesia, facial nerve paralysis due to anesthetic technique, mandibular fracture, bleeding, and other minor risks. After this, the patients were instructed that they could quit the research at any moment. These terms explained the study objectives and justifications, the benefits and risks to which the subjects were exposed, and the other items described in the National Health Council's Guidelines (Resolution CNS 196/96).

\section{Patients and Subjects}

This study involved 60 subjects presented as healthy subjects fit with the inclusion criteria (ASA I-II), never-smokers, between the ages of 18 and 35 years, with an indication of removal of the mandibular third molars with at least $2 / 3$ of the root formed (Class I or II; Position A/B from Pell and Gregory). All 
surgical procedures required bony removal and tooth sectioning in order to extract the impacted third molars.

Patients evaluated might present with the inclusion criteria established by the authors, which were:

1. Healthy patients with no local and systemic disorders.

2. Aged between 18 and 35 years.

3. Need of removal lower third molars with at least $2 / 3$ of root formation, evaluated by radiographic exam.

Besides that, patients which did not present the necessary characteristics to participate in the study were excluded. The criteria were:

1. Patients presented lower third molars on C position, according to Pell \& Gregory classification.

2. Local clinical signs which could not indicate the surgical procedure, as pericoronitis, odontogenic cysts and tumors associated or not with the third molar, trauma in the region, or any symptoms that indicate the presence of infection.

3. Presence of any systemic disorder as well diabetes, hypertension, hyperthyroidism, osteoporosis, gastrointestinal diseases that compromise the result of the surgery or any disease which impedes the use of drugs prescribed in this study.

4. Patients which used any drug in the last 30 days previously to the surgical procedure.

5. Patients with hypersensitivity of any drug used in this study.

6. Patients who have intolerance to the other materials that will be used in the research, such as $0.5 \%$ alcoholic chlorhexidine solution, $0.12 \%$ chlorhexidine gluconate solution and $4 \%$ articaine hydrochloride solution with epinephrine 1: 100,000

7. Female patients which were in the menstrual period or pregnant period and lactation.

\section{Sample size calculation}

A power test was calculated to obtain the sample size, it was based on a previous pilot study (mean difference $=1.87$; standard deviation $=1.75$ ) [22], which demonstrated the need for fourteen samples (teeth) for $80 \%$ of the power test, the authors added a total of sixteen samples per group. Thus, to obtain more homogeneous data (95\% of the power test), 20 samples (teeth) were selected for each group, totaling 60 patients. The test was applied by SigmaPlot 12.0 (Exakt Graphs and Data Analysis, San Jose, CA, USA).

\section{Experimental Groups}

Thus, a total of one hundred teeth from 60 subjects were divided into five groups $(n=20)$ : DEX, which represented subjects who received $8 \mathrm{mg}$ of dexamethasone (Laboratório Teuto Brasileiro s/a 17159229000176, Anápolis, GO, Brazil, code: 12804 - [797728]); DEX + ETO, which represented subjects who received $8 \mathrm{mg}$ of dexamethasone plus $300 \mathrm{mg}$ of etodolac (Laboratório Apsen Farmacêutica, São Paulo, Brazil); DEX + LOX, which represented subjects who received $8 \mathrm{mg}$ of dexamethasone plus $60 \mathrm{mg}$ 
of loxoprofen (Daiichi Sankyo Brasil, Barueri, Brazil); DEX + KET, which represented subjects who received $8 \mathrm{mg}$ of dexamethasone plus $10 \mathrm{mg}$ of ketorolac (União Química, São Paulo, Brazil); and DEX + IBU, which represented subjects who received $8 \mathrm{mg}$ of dexamethasone plus $600 \mathrm{mg}$ of ibuprofen (Prati Donaduzzi, Toledo, Brazil). The drugs were administered 1 hour before surgery and administered orally. The surgical interventions were timed from the beginning of the incision until the end of the last suture.

\section{Randomization}

Subject randomization was performed by a researcher (L.P.F.), who selected groups using the envelope system. The envelope contained papers on which the five groups' names were written, and a random selection was performed. If the subject presented with two lower third molars, which was compatible with the inclusion criteria, the subject underwent a double draw and could be allocated to two groups. The drugs were given to the subjects by the same researcher. All the drugs were manipulated, the capsules were equally the same and were given in a surgical envelope to avoid the recognize of the drug by the patient and create a bias. The surgeon (G.A.C.M.) and the researcher who conducted the analysis (T.O.B.P.) did not know the groups to groups to which the subjects were assigned, characterizing a tripleblind clinical trial.

When a subject had bilateral third molars, the choice to initially operate on the right or left side was also determined by the researcher (L.P.F.) using the envelope system. In this situation, the surgeries were conducted unilaterally with a minimum interval of 21 days between the extraction procedures.

\section{Surgical Procedures}

The surgical procedures were performed by the same surgeon. All subjects received preoperative antibiotic therapy with $2 \mathrm{~g}$ of amoxicillin 1 hour before the surgical procedure. Intrabuccal antisepsis was performed with vigorous mouth washing for 1 minute with an aqueous solution of $0.12 \%$ chlorhexidine digluconate, followed by extraoral antisepsis with $0.5 \%$ chlorhexidine alcohol solution. The anesthetic technique employed comprised a regional blockade of the inferior alveolar, buccal, and lingual nerves. This was performed using a reflux syringe with a long 27-gauge gingival needle for injection of $2 \%$ mepivacaine hydrochloride with epinephrine 1:100,000 (Mepiadre ${ }^{\circ}, \mathrm{DFL}$ ) at a maximum volume of 4.5 $\mathrm{ml}$, equivalent to 2.5 tubes.

A triangular linear flap was made with a number 15 scalpel blade in the distal region of the lower second molar in association with a buccal releasing incision in the mesial aspect of the second molar. Following this, mucoperiosteal detachment was performed with periosteal relief and a retractor was used to expose the operative field. Osteotomy was performed using a model 702 carbide-tipped drill bit mounted on a high-speed pen, in addition to abundant irrigation with sterile saline $\mathrm{NaCl} 0.9 \%$. Dental removal was completed with curved and straight extractors of the Seldin type $\left(n^{\circ} 2,1 R\right.$, or $\left.1 \mathrm{~L}\right)$, followed by careful inspection for the removal of pericoronal follicles with curettes and Kelly curve tweezers.

The bone margins were trimmed to remove bone spicules using a bone file, with abundant irrigation using sterile saline $\mathrm{NaCl}$ 0.9\%. Thereafter, sutures were performed with nylon 5.0 (Ethicon ${ }^{\circledR}$, Johnson \& 
Johnson, Brazil). Surgical interventions were performed in the morning and afternoon (between 08 am and $6 \mathrm{pm})$ in a temperature environment control.

After the surgical procedure, all subjects received 12 tablets of $750 \mathrm{mg}$ paracetamol (not identified to the subject, in white tablet form) and were advised to take 1 tablet in case of pain, with a minimum interval of 6 hours between administrations of the analgesic. Subjects were instructed to recording a log of all relevant variables such as VAS score at each timepoint, and when analgesics were taken.

Immediately after the surgical procedures, the subjects were prescribed a cold, liquid, pasty, hyperproteinbased diet for the first 48 hours postoperatively, as well as other aspects of general care, such as avoiding physical exertion and sun exposure. Subjects were advised not to use cold compresses during the postoperative period. Any subject who developed postoperative complications, such as bleeding and alveolar osteitis was treated and consequently excluded from the study. Follow-up visits were scheduled at 48 hours and 7 days postoperatively to evaluate for edema and MMO. Sutures were removed at the 7day postoperative mark.

\section{Primary outcomes}

For this study, the primary outcome variables were the assessment of pain (visual analog scale VAS, and number of rescue analgesics, NRA). Salivary PGE2 concentration, edema and MMO were secondary outcomes variables.

Pain was measured using a visual analog scale (VAS). During the postoperative period, all subjects received a VAS protocol containing a linear chart with a scale from 0 to 10 . The subjects were instructed to point out the level of postoperative pain on the chart at $6,12,24,48$, and 72 hours and 7 days after the surgical procedure. A VAS score of 0 represented the absence of postoperative pain, whereas a score of 10 represented the worst pain the subject had experienced. ${ }^{[10,17]}$ The weighted average corresponding to the values of every subject in each group was obtained.

Another outcome measure for pain involved the number of analgesics consumed by the subject during postoperative period. Subjects were instructed to record the time of first analgesic consumption. The patients were no induced to consumed or not the drugs, only were informed that were usually drugs destined to relieve pain, edema and trismus and might be used only if were extremely necessary for a rescue way. The weighted average corresponding to the values of every subject in each group was obtained.

\section{Secondary outcomes}

The salivary collection was performed before subjects took the preoperative drug, prior to the surgical procedure, and 48 hours after the surgical procedure. Saliva was collected directly in a salivate tube (Salivette ${ }^{\circledR}$; Genese Produtos Diagnósticos Ltda, São Paulo, SP, Brazil). The subjects were informed not to eat or brush their teeth in the 2 hours preceding the collection procedure. The tubes were properly capped and stored at $-20^{\circ} \mathrm{C}$ to keep the samples stable. The salivates were centrifuged at $1000 \mathrm{~g}$ for one minute, resulting in a clean and fluid saliva sample that was used to determine the PGE2 salivary 
concentration. Salivary PGE2 was measured by competitive enzyme-linked immunosorbent assay (ELISA) method using a commercial kit (Diametra DKO020, Milano, Italy).

Edema measurement was performed using a three-point analysis with a tape measure. Measurements were made of the mandibular angle to the lateral canthus, tragus to labial commissure, and tragus to pogonion at the preoperative, 48 hours postoperative, and 7 days postoperative periods (Fig. 1). ${ }^{[18]}$ The values obtained were recorded in the subjects' individual files. The researcher (T.O.B.P.) who performed these measurements was blinded and also determined all the results of the analyses of this study. To test intra-observer variability and increase measurement precision, all measurements were repeated by the same operator 3 times to ensure reliability of the method and consistency of the operator ${ }^{[19]}$. To assess postoperative edema, a weighted average of the three-point measurements was calculated: 48-hour postoperative values were subtracted from preoperative values to represent the 48-hour postoperative edema. The representative 7-day postoperative edema was obtained by subtracting the postoperative 7day values from preoperative values.

Maximum mouth opening was evaluated using measurements in millimeters made with a digital caliper (Mitutoyo ${ }^{\circledR}$, Sakado, Japan) between the incisal edge of the upper central incisors and the lower central incisors on the right side. The measurements were performed preoperatively, as well as 48 hours and 7 days after the surgical procedure. ${ }^{[10,17]}$

For the calibration of the researcher, four patients were selected to MMO and edema measurements, before the beginning of the study. The analysis was performed by the same researcher twice in a 21 days of interval. The Kappa test showed the concordance intra-examinator $(K>0.95)$

\section{Follow-up}

The follow-up time of the patients after the analyses ( 7 days) varied from 2 to 3 months after surgery.

\section{Statistical Analysis}

All quantitative data underwent a statistical analysis and homoscedasticity statistical testing (ShapiroWilk test) for homogeneity or heterogeneity distribution. For VAS, edema, and MMO, a two-way ANOVA and Tukey posttests were applied, and results were considered significant when $P<0.05$. For PEG2 concentration, a one-way ANOVA and Tukey posttests were performed, results were considered significant when $P<0.05$. Only NRA failed in the homoscedasticity statistical test, and a Kruskal-Wallis test was applied. An intention to treat analysis was performed for all randomized patients who were included in this study.

\section{Results}

\section{Demographic data}

A total of 125 subjects were screened for eligibility. Sixty-one subjects were excluded. Fifty subjects did not meet the inclusion criteria and 11 subjects declined to participate in the study. Thus, 64 subjects were 
randomized and divided into five groups. All 64 subjects received the planned intervention, however, at the follow-up visit, four subjects were excluded due to postoperative dry socket alveolitis and the use of drugs/medicaments not related to the study as described in the exclusion criteria (Fig. 2). Demographic data regarding mean age, sex, and number of teeth removed are shown in Table 1.

Table 1

Characteristics of the patients.

\begin{tabular}{|ll|}
\hline Variable & Value \\
\hline Number of patients & 60 \\
\hline Age (years) & \\
\hline Mean \pm SD & $25,365 \pm 4,8745$ \\
\hline Range & $18-35$ \\
\hline Sex (\%) & \\
\hline Male & $18 \%$ \\
\hline Female & $82 \%$ \\
\hline Teeth (patients) & 24 \\
38 & 40 \\
48 & 36 \\
38 and 48 & 100 \\
Total & \\
\hline
\end{tabular}

\section{Visual analog scale (VAS)}

The VAS data showed that, during the first six hours, DEX + ETO (mean \pm standard deviation - SD) (1.9 \pm $0.3)$ and DEX + KET $(2.1 \pm 0.4)$ decreased pain perception significantly, compared with DEX alone $(5 \pm 0.6)$, $\mathrm{DEX}+\mathrm{IBU}(4.9 \pm 0.34)$, and DEX + LOX $(3.9 \pm 0.42)(P<0.05-$ Tukey test $)$.

At 12 hours postoperative, DEX + ETO $(2 \pm 0.35)$ and DEX + KET $(2.1 \pm 0.45)$ continued to decrease pain perception, but at this point, DEX alone $(2.9 \pm 0.64)$ showed similar values. DEX + IBU ( $3.9 \pm 0.87)$; and DEX + LOX $(3.8 \pm 0.76)$ still showed high pain perception values at this time.

After the first postoperative day (24 hours, 48 hours, 72 hours, and 7 days), DEX + ETO showed the lowest pain perception values. However, DEX showed similar values. DEX + KET maintained its previous average, 
and DEX + IBU and DEX + LOX showed the worst pain perception values during all postoperative periods (Fig. 3).

\section{Number of rescue analgesics (NRA)}

NRA data showed that subjects in the DEX + ETO group consumed the fewest analgesics during postoperative period. The average consumption was 1.2 analgesics during the entire postoperative recovery period (1.2 \pm 0.36$)$. After this group, subjects in the DEX $(2 \pm 0.43)$ and DEX + KET $(2 \pm 0.41)$ groups an average of 2 analgesics during postoperative recovery period. Subjects in the DEX + LOX group consumed an average of 1.9 analgesics $(1.9 \pm 0.44)$. Subjects in the DEX + IBU group consumed an average of 3 analgesics $(3 \pm 0.35)$ during the postoperative recovery period (Fig. 4).

\section{Prostaglandin E2 salivary concentration (PGE2)}

Data about the salivary concentration of prostaglandin E2 (PGE2) 48 hours after the surgical procedure indicated that the DEX group (average $0.2 \mathrm{ng} / \mathrm{ml}$ ) was the only one in which there was a decrease of concentration of PGE2 compared to the preoperative period (average $0.7 \mathrm{ng} / \mathrm{ml}$ ). Subjects who only took DEX 1 hour before the surgery showed an $80 \%$ decrease in PGE2 48 hours after surgery. All other groups showed an increase in PGE2 concentration 48 hours after surgery. Subjects who took DEX + KET showed a $66.6 \%$ increase in PGE2 concentration. This data was followed by PGE2 concentration levels for the DEX + ETO (99.2\% increase; Preoperative: $1.8 \mathrm{ng} / \mathrm{ml}$; postoperative: $2.7 \mathrm{ng} / \mathrm{ml})$, DEX + LOX $(339.2 \%$ increase; Preoperative: $0.8 \mathrm{ng} / \mathrm{ml}$; Postoperative: $2.8 \mathrm{ng} / \mathrm{ml})$ and DEX + IBU $(2956.25 \%$ increase; Preoperative: $0.4 \mathrm{ng} / \mathrm{ml}$; Postoperative: $5 \mathrm{ng} / \mathrm{ml}$ ) groups. Values for 48-hour postoperative salivary PGE2 concentration indicated significant differences between the DEX and DEX + IBU groups $(P<0.05-$ Tukey test) and between DEX + KET and DEX + IBU ( $P<0.05$ - Tukey test) (Fig. 5).

\section{Edema}

The DEX + LOX $(3.1 \pm 0.2 \mathrm{~mm})$ and DEX + IBU $(3.12 \pm 0.32 \mathrm{~mm})$ groups showed lower values for edema 48 hours after the surgical procedure. These groups were followed by DEX + KET $(3.6 \pm 0.2 \mathrm{~mm})$ and DEX + ETO $(4.1 \pm 0.2 \mathrm{~mm})$, which showed similar values to DEX alone $(4.2 \pm 0.2 \mathrm{~mm})$. After 7 days, all groups showed low values for edema except DEX +ETO $(2.2 \pm 0.2 \mathrm{~mm})$. There was no statistical difference among the groups $(P>0.05-$ Tukey test) (Fig. 6).

\section{Maximum mouth opening (MMO)}

The DEX + KET group $(27.2 \pm 5.18 \mathrm{~mm})$ showed the lowest values for 48 hours postoperative MMO. The DEX group $(35.6 \pm 7.96 \mathrm{~mm})$ showed higher values for 48 hours postoperative MMO $(P<0.05-$ Tukey test). The other groups showed similar values compared to DEX group $(P>0.05$; DEX + ETO: $35.2 \pm 8.33$; DEX + IBU: $31 \pm 7.83$; DEX + LOX: $28.2 \pm 3.88$ ). After 7 days, all groups showed a decrease in trismus (or increase in $\mathrm{MMO})$, showing similar values for all comparisons $(P>0.05)$ (Fig. 7).

\section{Discussion}

This study aimed to evaluate whether benefits exist with a combination of NSAIDs plus DEX in decreasing postoperative pain, edema, and $\mathrm{MMO}$ following third molar surgery. Prior studies are unclear 
whether the combination of these drugs could provide an advantage in postoperative period, which justifies the clinical use of various drugs preoperatively. However, the combination of some NSAIDS plus DEX seems to improve symptoms in the first postoperative hours of acute pain.

The preemptive use of steroids for third molar surgery, mainly DEX, is well established, and provides positive results regarding a comfortable postoperative period for the patients. ${ }^{[6,20,21]} \mathrm{A} 2008$ clinical study by Laureano-Filho and colleagues ${ }^{[22]}$ compared a preoperative dose of $4 \mathrm{mg}$ and $8 \mathrm{mg}$ of DEX in third molar surgeries and observed that there was a significant difference between the doses regarding postoperative $\mathrm{MMO}$ and edema, but not postoperative pain, as was observed in another study. ${ }^{[23]}$ This lack of effect on pain may be explained by the ineffectiveness of DEX in reducing prostaglandins at the site of an injury. ${ }^{[24]}$ Another possible explanation for this phenomenon is that cortisol naturally inhibits pituitary beta-endorphins, which are potent endogenous analgesic present in the peripheral circulation. ${ }^{25]}$

Some clinical trials have suggested that the combination of steroids and NSAIDS improves preemptive effects on MMO, edema, and pain compared to steroids alone. ${ }^{[4,13]}$ This study found that the combination of DEX plus several NSAIDS (DEX + ETO, DEX + KET, DEX + IBU, and DEX + LOX) showed no significant difference in the edema and MMO parameters. The exception was the combination of DEX + KET, which showed a significantly higher value for 48-hour postoperative MMO compared with DEX alone. These results could be explained because, as noted above, the use of preoperative DEX alone is well established and provides positive results regarding the improvement of postoperative edema and MMO. ${ }^{[6,20,21]}$

Although data were obtained about postoperative pain, the VAS analysis showed that patients who took preoperative DEX + ETO and DEX + KET exhibited significantly lower pain perception during the first 6 postoperative hours compared with all the groups. At 12 hours postoperative, the DEX group showed similar values to the DEX + ETO and DEX + KET groups, whereas the DEX + LOX and DEX + IBU groups maintained higher pain values during all periods. After the first day (24 hours), subjects who took DEX + KET showed an increase in pain perception compared with the DEX and DEX + ETO groups, which had lower VAS values during the postoperative period. There was no significant difference between these two groups.

NRA did not significantly differ among the groups; however, it seemed to be lower for the DEX + ETO (average of 1.2 postoperative analgesics) group compared to the other groups. In addition, the DEX + IBU group presented the highest consumption of all groups. However, it is important to highlight that even though NRA was higher for DEX + IBU group, subjects who received this drug preoperatively took an average of three analgesics during the seven postoperative days. This value is well below what is usually prescribed in most practices, which also often include three days of acetaminophen with opioids at an interval of 6 hours. ${ }^{[26,27]}$

DEX alone was the only preoperative therapy that decreased the salivary expression of PGE2 48 hours after the surgical procedure. The other groups showed an increase in salivary PGE2. However, the DEX + 
ETO and DEX + KET groups showed a discreet increase, whereas the DEX + IBU and DEX + LOX groups showed a significant increase in PGE2. This data disagrees with the VAS, which showed that the DEX, $D E X+E T O$, and DEX + KET groups presented similar pain perception values during the entire postoperative period. However, PGE2 is not the only pain mediator released during an inflammation response. Other algogenic substances are generated from arachidonic acids, such as bradykinin, leukotrienes, tumoral necrose factors (TNF-a) and interleukins. ${ }^{[28]}$ Although the PGE2 expression values were higher, VAS evaluated the subjects' pain perception. Thus, even though the drugs had no effect on PGE2 expression, they might have decreased the subjects' pain perception. Laureano-Filho and colleagues $^{[22]}$ showed that $8 \mathrm{mg}$ of DEX 1 hour before surgery decreased the expression of PGE2 and thromboxane A2 at the surgical site, but this had a minimal effect on reported pain the day of the surgery. Similar results were found in another trial with methylprednisolone $125 \mathrm{mg}^{[1]}$.

There is no consensus about the preemptive combination of DEX and an NSAID. Although trials have shown great results for this therapy, this study observed that not all combinations produced good results. $D E X+I B U$ and DEX + LOX presented poor results for all parameters, and DEX alone seems sufficient to relieve postoperative pain. Currently, the medical field seeks to decrease the number of drugs prescribed to patients. Furthermore, NSAIDs have several adverse effects, such as cardiovascular and gastrointestinal events. ${ }^{[29]}$ Preemptive DEX alone performed well for postoperative pain, edema, MMO and, decreased salivary PGE2, but KET and ETO, when combined with DEX in a preemptive way, showed similar results to DEX alone in terms of VAS scores 7 days after the surgical procedure and significantly decreased patients' pain perception at 6 hours after surgery, compared to DEX alone, which resulted in the worst acute pain after the procedure. This demonstrates important benefits for patients' postoperative comfort.

Indeed, ETO and KET have proven effective against pain when prescribed after third molar surgeries. ${ }^{[10,30 \text {, }}$ ${ }^{31]}$ When combined with DEX, a single preoperative dose of KET and/or ETO seems to significantly reduce acute pain during the first few hours, and there is no need to prescribe any postoperative NSAID except a rescue analgesic. This study presented some limitations. It did not account for other algogenic cytokine expressions did not evaluate other NSAIDs, so more trials should be designed to establish a clinical consensus about this field. However, the use of specific NSAIDs combined with $8 \mathrm{mg}$ of DEX after third molar surgeries might provide patients with postoperative benefits and should be considered in the dentistry routine.

\section{Conclusion}

It can conclude that the preemptive use of steroids with NSAIDS does not always provide more postoperative benefits than steroids alone, but the combinations involving KET and ETO significantly improved patients' postoperative pain during the first few hours.

\section{Declarations}




\section{Acknowledgments}

The authors would like to express gratitude for support and scholarship from the Coordination for the Improvement of Higher Education Personnel (CAPES) in the PrINT Program (Fellowship Research \#88887.373422/2019-00).

\section{COMPLIANCE WITH ETHICAL STANDARDS}

Conflict of interest: Gustavo Antonio Correa Momesso declares that has no conflict of interest; Gustavo Augusto Grossi Oliveira declares that has no conflict of interest; William Phillip Pereira da Silva declares that has no conflict of interest; Renan Akira declares that has no conflict of interest; Fernando Chiba declares that has no conflict of interest; Tárik Ocon B Polo declares that has no conflict of interest; Tiburtino José Lima Neto declares that has no conflict of interest; Bárbara Ribeiro Rios declares that has no conflict of interest; Ana Paula Farnezi Bassi declares that has no conflict of interest; Doris Hissako Sumida declares that has no conflict of interest; Michael Han declares that has no conflict of interest; Michael Miloro declares that has no conflict of interest; Leonardo P Faverani declares that has no conflict of interest.

Ethics: All procedures performed in studies involving human participants were in accordance with the ethical standards of the institutional and/or national research committee (\#818.680) and with the 1964 Helsinki declaration and its later amendments or comparable ethical standards.

Informed consent: Informed consent was obtained from all individual participants included in the study.

Funding: This study was financed in part by the Coordenação de Aperfeiçoamento de Pessoal de Nível Superior - Brazil (CAPES) - Finance Code 001.

\section{References}

1. Sisk AL, Bonnington GJ: Evaluation of methylprednisolone and flurbiprofen for inhibition of the postoperative inflammatory response. Oral Surg Oral Med Oral Pathol 60:137, 1985

2. Y US, Erdogan O, Esen E, Karsli ED: Comparison of the effects of 2 doses of methylprednisolone on pain, swelling, and trismus after third molar surgery. Oral Surg Oral Med Oral Pathol Oral Radiol Endod 96:535, 2003

3. Lima TC, Bagordakis E, Falci SGM, Dos Santos CRR, Pinheiro MLP: Pre-Emptive Effect of Dexamethasone and Diclofenac Sodium Associated With Codeine on Pain, Swelling, and Trismus After Third Molar Surgery: A Split-Mouth, Randomized, Triple-Blind, Controlled Clinical Trial. J Oral Maxillofac Surg 76:60, 2018

4. Barbalho JC, Vasconcellos RJ, de Morais HH, Santos LA, Almeida RA, Rebelo HL, Lucena EE, de Araujo SQ: Effects of co-administered dexamethasone and nimesulide on pain, swelling, and trismus following third molar surgery: a randomized, triple-blind, controlled clinical trial. Int J Oral Maxillofac Surg 46:236, 2017 
5. Kissin I: Preemptive analgesia. Anesthesiology 93:1138, 2000

6. Schmelzeisen R, Frolich JC: Prevention of postoperative swelling and pain by dexamethasone after operative removal of impacted third molar teeth. Eur J Clin Pharmacol 44:275, 1993

7. Huffman GG: Use of methylprednisolone sodium succinate to reduce postoperative edema after removal of impacted third molars. J Oral Surg 35:198, 1977

8. Beirne OR, Hollander B: The effect of methylprednisolone on pain, trismus, and swelling after removal of third molars. Oral Surg Oral Med Oral Pathol 61:134, 1986

9. Diaz-Gonzalez F, Sanchez-Madrid F: NSAIDs: learning new tricks from old drugs. Eur J Immunol 45:679, 2015

10. Silva de Oliveira JC, Grossi de Oliveira GA, Bassi AP: Comparative Assessment of the Effect of Ibuprofen and Etodolac on Edema, Trismus, and Pain in Lower Third Molar Surgery: A Randomized Clinical Trial. J Oral Maxillofac Surg 74:1524, 2016

11. Calvo AM, Zupelari-Goncalves P, Dionisio TJ, Brozoski DT, Faria FA, Santos CF: Efficacy of piroxicam for postoperative pain after lower third molar surgery associated with CYP2C8*3 and CYP2C9. J Pain Res 10:1581, 2017

12. Pouchain EC, Costa FW, Bezerra TP, Soares EC: Comparative efficacy of nimesulide and ketoprofen on inflammatory events in third molar surgery: a split-mouth, prospective, randomized, double-blind study. Int J Oral Maxillofac Surg 44:876, 2015

13. Bauer HC, Duarte FL, Horliana AC, Tortamano IP, Perez FE, Simone JL, Jorge WA: Assessment of preemptive analgesia with ibuprofen coadministered or not with dexamethasone in third molar surgery: a randomized double-blind controlled clinical trial. Oral Maxillofac Surg 17:165, 2013

14. Moore PA, Brar P, Smiga ER, Costello BJ: Preemptive rofecoxib and dexamethasone for prevention of pain and trismus following third molar surgery *. Oral Surg Oral Med Oral Pathol Oral Radiol Endod 99:E1, 2005

15. Dionne RA: Suppression of dental pain by the preoperative administration of flurbiprofen. Am J Med 80:41, 1986

16. Rickham PP: Human Experimentation. Code of Ethics of the World Medical Association. Declaration of Helsinki. Br Med J 2:177, 1964

17. Antunes AA, Avelar RL, Martins Neto EC, Frota R, Dias E: Effect of two routes of administration of dexamethasone on pain, edema, and trismus in impacted lower third molar surgery. Oral Maxillofac Surg 15:217, 2011

18. Markovic A, Todorovic L: Effectiveness of dexamethasone and low-power laser in minimizing oedema after third molar surgery: a clinical trial. Int J Oral Maxillofac Surg 36:226, 2007

19. da Silveira HL, Silveira HE: Reproducibility of cephalometric measurements made by three radiology clinics. Angle Orthod 76:394, 2006

20. Alexander RE, Throndson RR: A review of perioperative corticosteroid use in dentoalveolar surgery. Oral Surg Oral Med Oral Pathol Oral Radiol Endod 90:406, 2000 
21. Klongnoi B, Kaewpradub P, Boonsiriseth $\mathrm{K}$, Wongsirichat N: Effect of single dose preoperative intramuscular dexamethasone injection on lower impacted third molar surgery. Int J Oral Maxillofac Surg 41:376, 2012

22. Laureano Filho JR, Maurette PE, Allais M, Cotinho M, Fernandes C: Clinical comparative study of the effectiveness of two dosages of Dexamethasone to control postoperative swelling, trismus and pain after the surgical extraction of mandibular impacted third molars. Med Oral Patol Oral Cir Bucal 13:E129, 2008

23. Alcantara CE, Falci SG, Oliveira-Ferreira F, Santos CR, Pinheiro ML: Pre-emptive effect of dexamethasone and methylprednisolone on pain, swelling, and trismus after third molar surgery: a split-mouth randomized triple-blind clinical trial. Int J Oral Maxillofac Surg 43:93, 2014

24. Dionne RA, Gordon SM, Rowan J, Kent A, Brahim JS: Dexamethasone suppresses peripheral prostanoid levels without analgesia in a clinical model of acute inflammation. J Oral Maxillofac Surg 61:997, 2003

25. Troullos ES, Hargreaves KM, Butler DP, Dionne RA: Comparison of nonsteroidal anti-inflammatory drugs, ibuprofen and flurbiprofen, with methylprednisolone and placebo for acute pain, swelling, and trismus. J Oral Maxillofac Surg 48:945, 1990

26. McQuay HJ, Carroll D, Guest P, Juniper RP, Moore RA: A multiple dose comparison of combinations of ibuprofen and codeine and paracetamol, codeine and caffeine after third molar surgery. Anaesthesia 47:672, 1992

27. Best AD, De Silva RK, Thomson WM, Tong DC, Cameron CM, De Silva HL: Efficacy of Codeine When Added to Paracetamol (Acetaminophen) and Ibuprofen for Relief of Postoperative Pain After Surgical Removal of Impacted Third Molars: A Double-Blinded Randomized Control Trial. J Oral Maxillofac Surg 75:2063, 2017

28. Dray A: Inflammatory mediators of pain. Br J Anaesth 75:125, 1995

29. Harirforoosh S, Asghar W, Jamali F: Adverse effects of nonsteroidal antiinflammatory drugs: an update of gastrointestinal, cardiovascular and renal complications. J Pharm Pharm Sci 16:821, 2013

30. Isiordia-Espinoza MA, Pozos-Guillen AJ, Martinez-Rider R, Herrera-Abarca JE, Perez-Urizar J: Preemptive analgesic effectiveness of oral ketorolac plus local tramadol after impacted mandibular third molar surgery. Med Oral Patol Oral Cir Bucal 16:e776, 2011

31. Akbulut N, Ustuner E, Atakan C, Colok G: Comparison of the effect of naproxen, etodolac and diclofenac on postoperative sequels following third molar surgery: a randomised, double-blind, crossover study. Med Oral Patol Oral Cir Bucal 19:e149, 2014

\section{Figures}



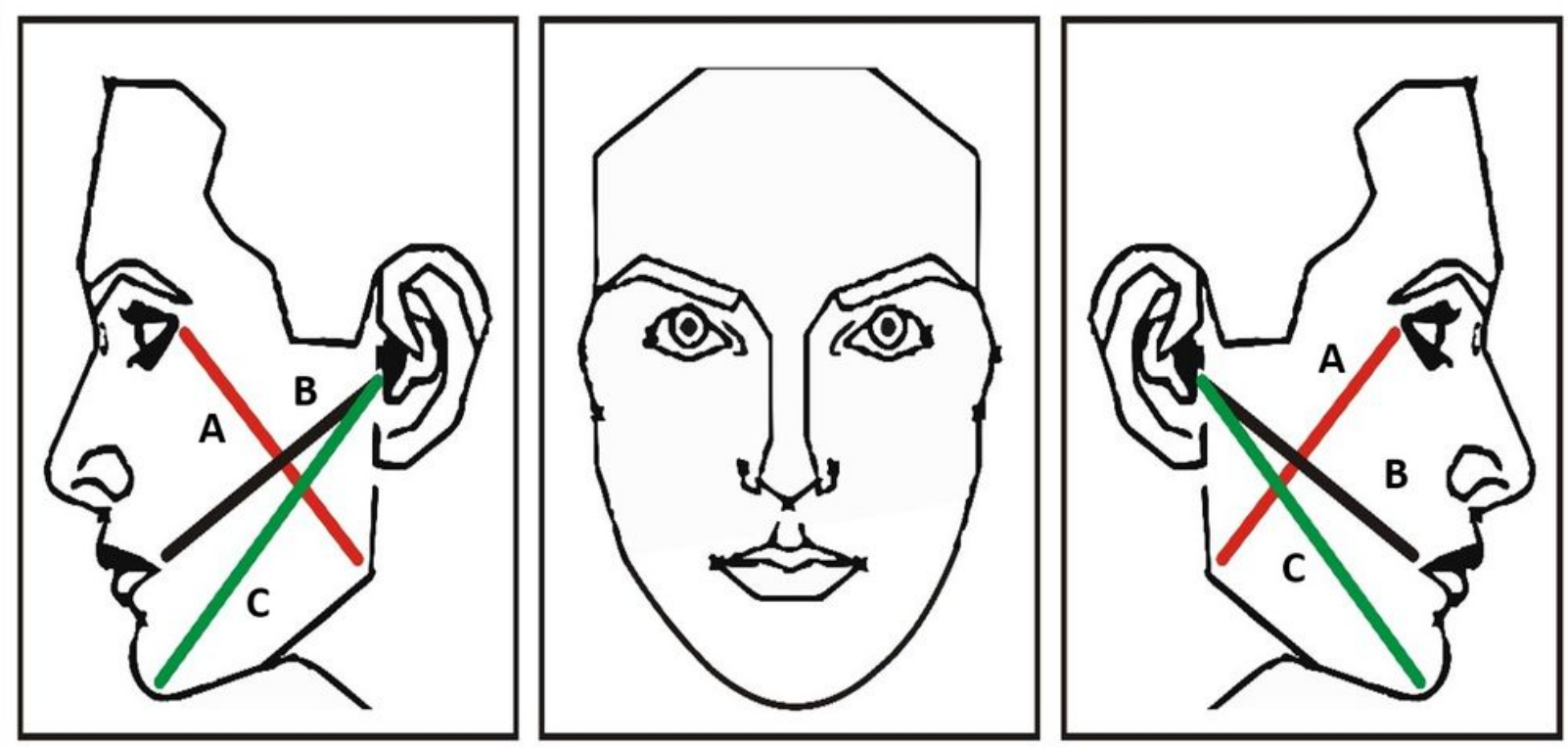

Figure 1

Representative scheme showing the topographic points measured for edema evaluation. The line A represented the point from mandibular angle up to corner of the eye. Line B represented the point from tragus up to labial commissure and line $\mathrm{C}$ represented the point from tragus up to pogonion. 


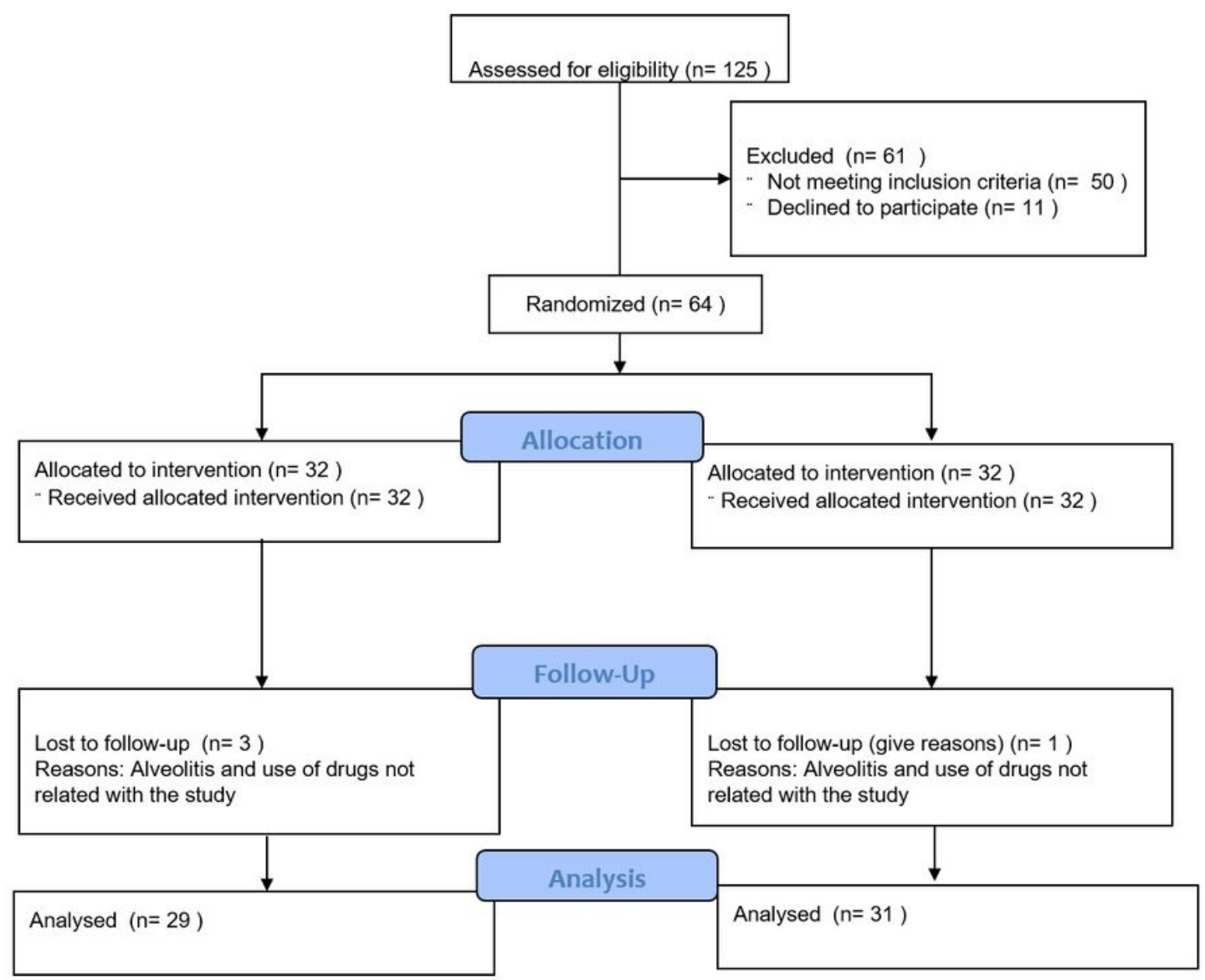

Figure 2

Flowchart of subjects screened according to CONSORT statement. 


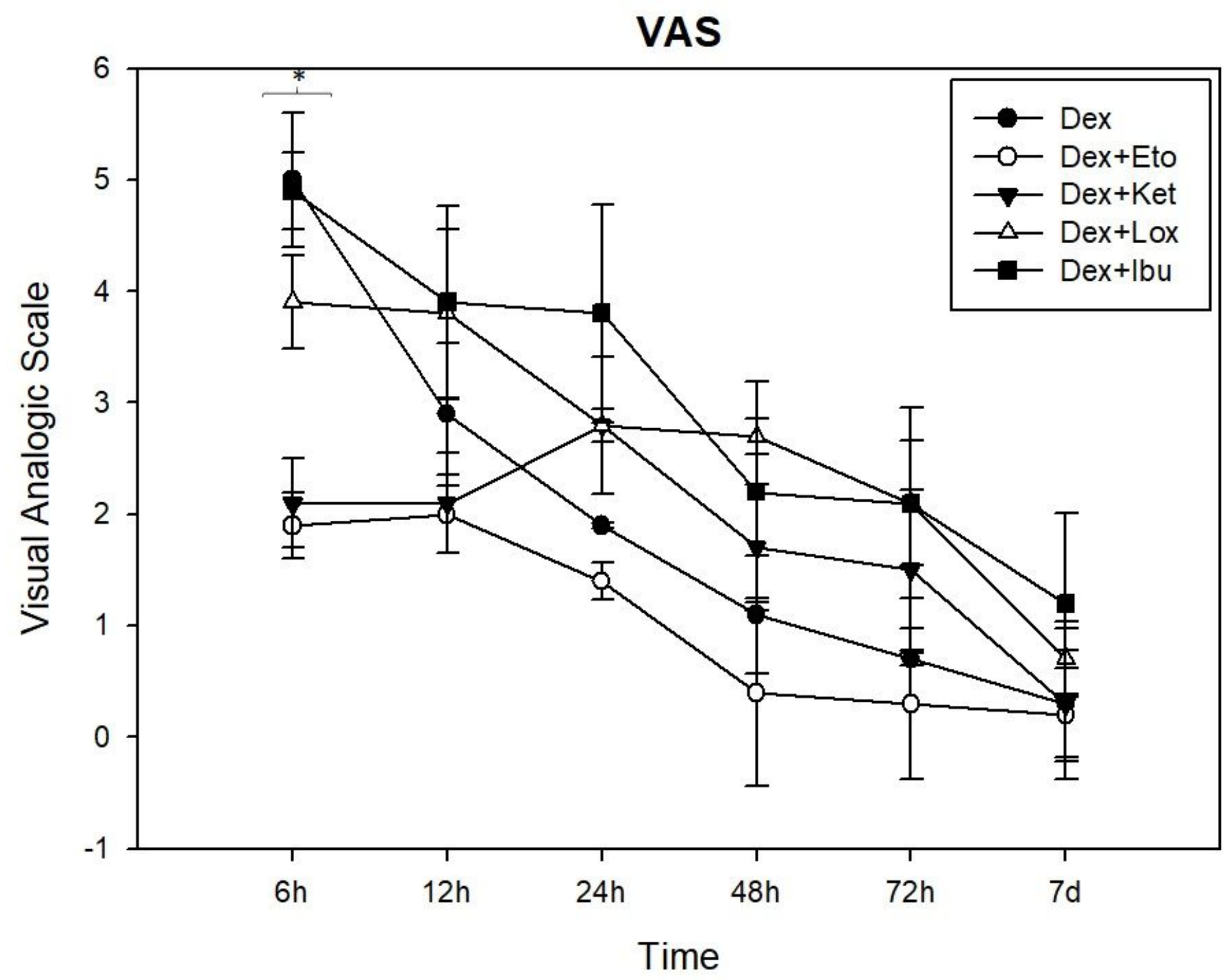

Figure 3

Data regarding VAS analysis. It was possible observed that at first 6 hours postoperative, pain perception from DEX+ETO and DEX+KET groups were significantly lower than DEX and DEX+IBU $(P<0.05-$ Tukey test). The other postoperative periods showed no significant difference between groups. 


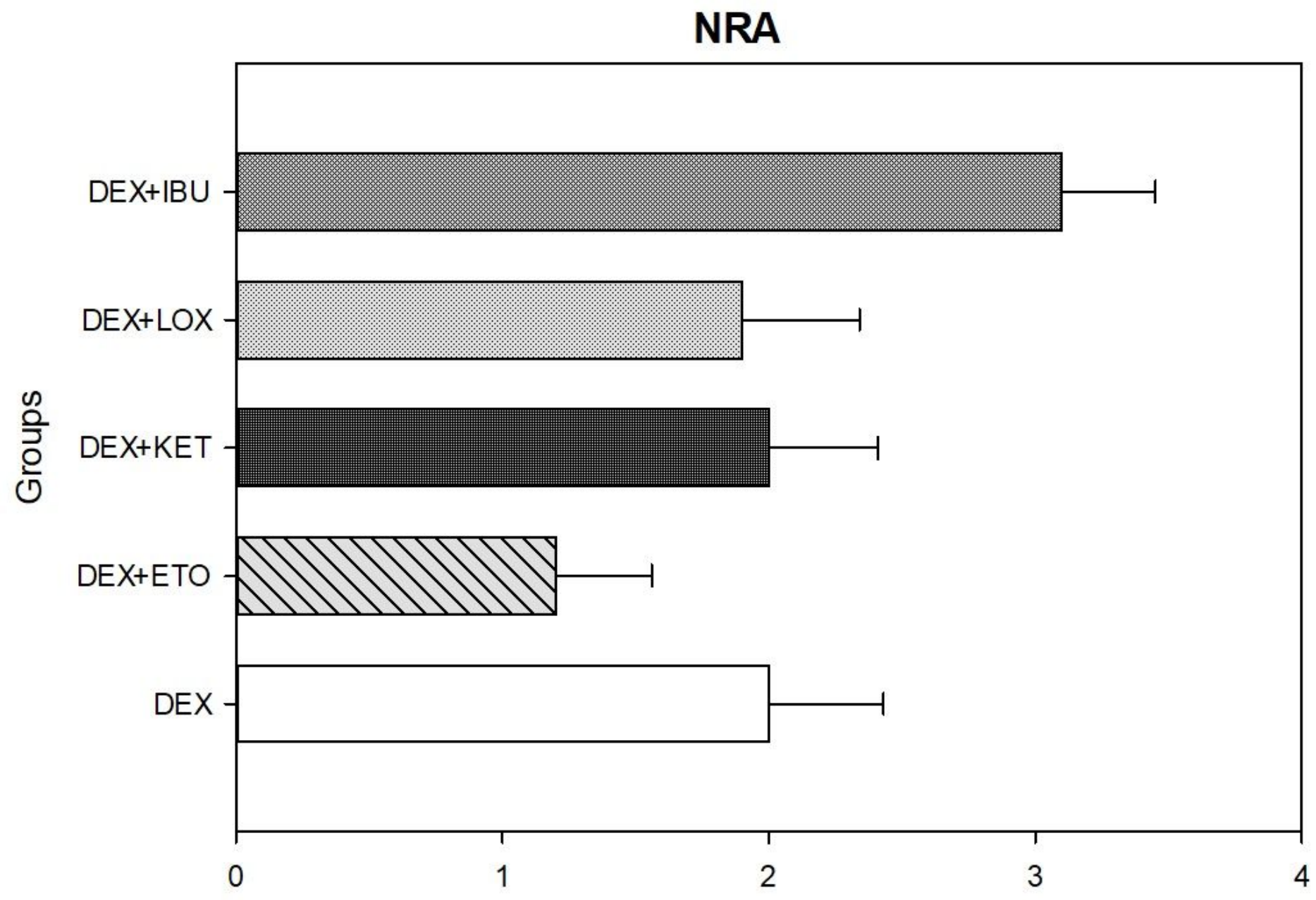

Figure 4

Chart regarding number of rescue analgesic consumption for 7 days postoperative. 


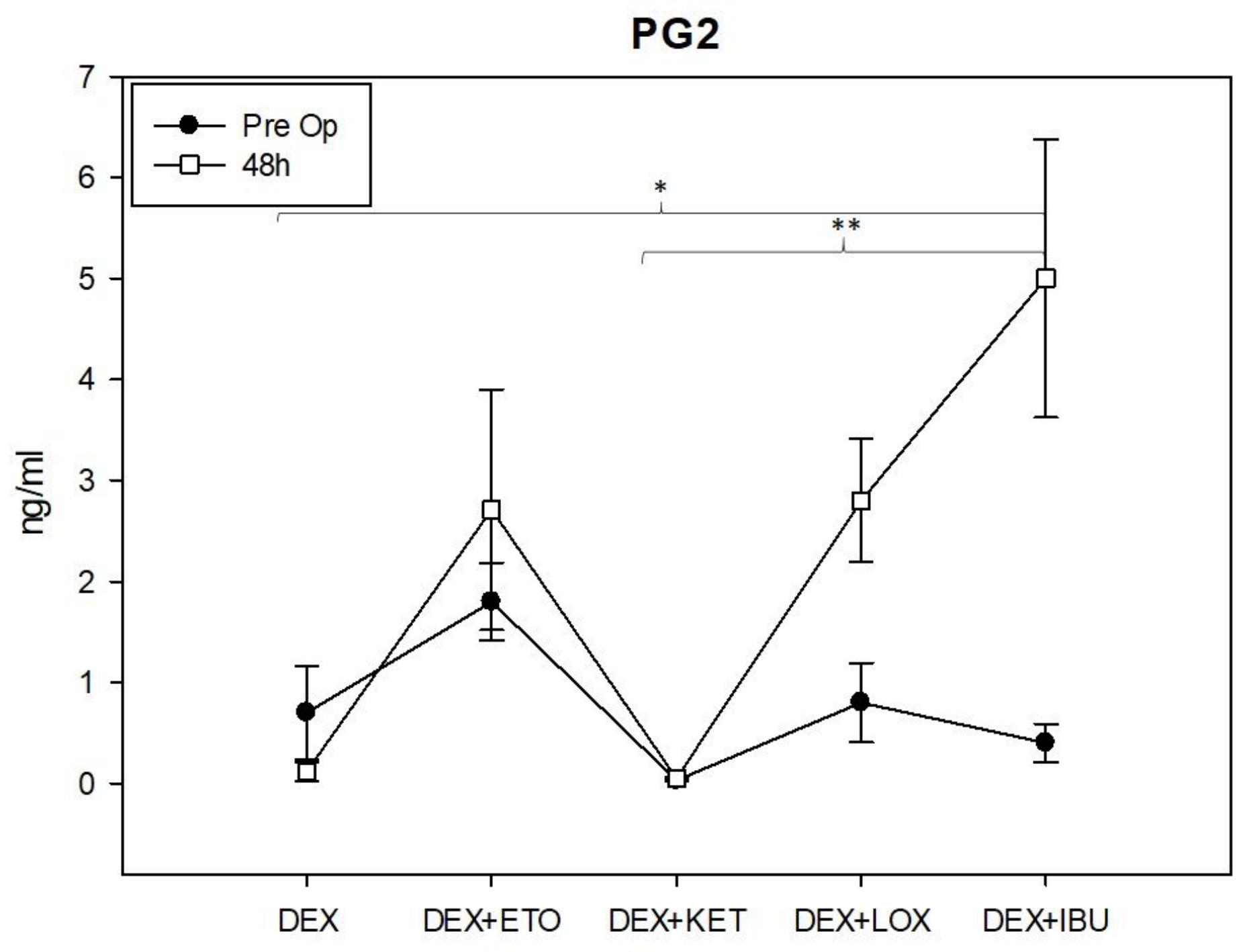

Figure 5

Chart regarding prostaglandin salivary E2 (PGE2) concentration. Data showed that DEX group was the only which decrease the PGE2 at 48 hours postoperative (80\%), while other groups showed an increase of PGE2 concentration at 48 hours postoperative. 
EDEMA

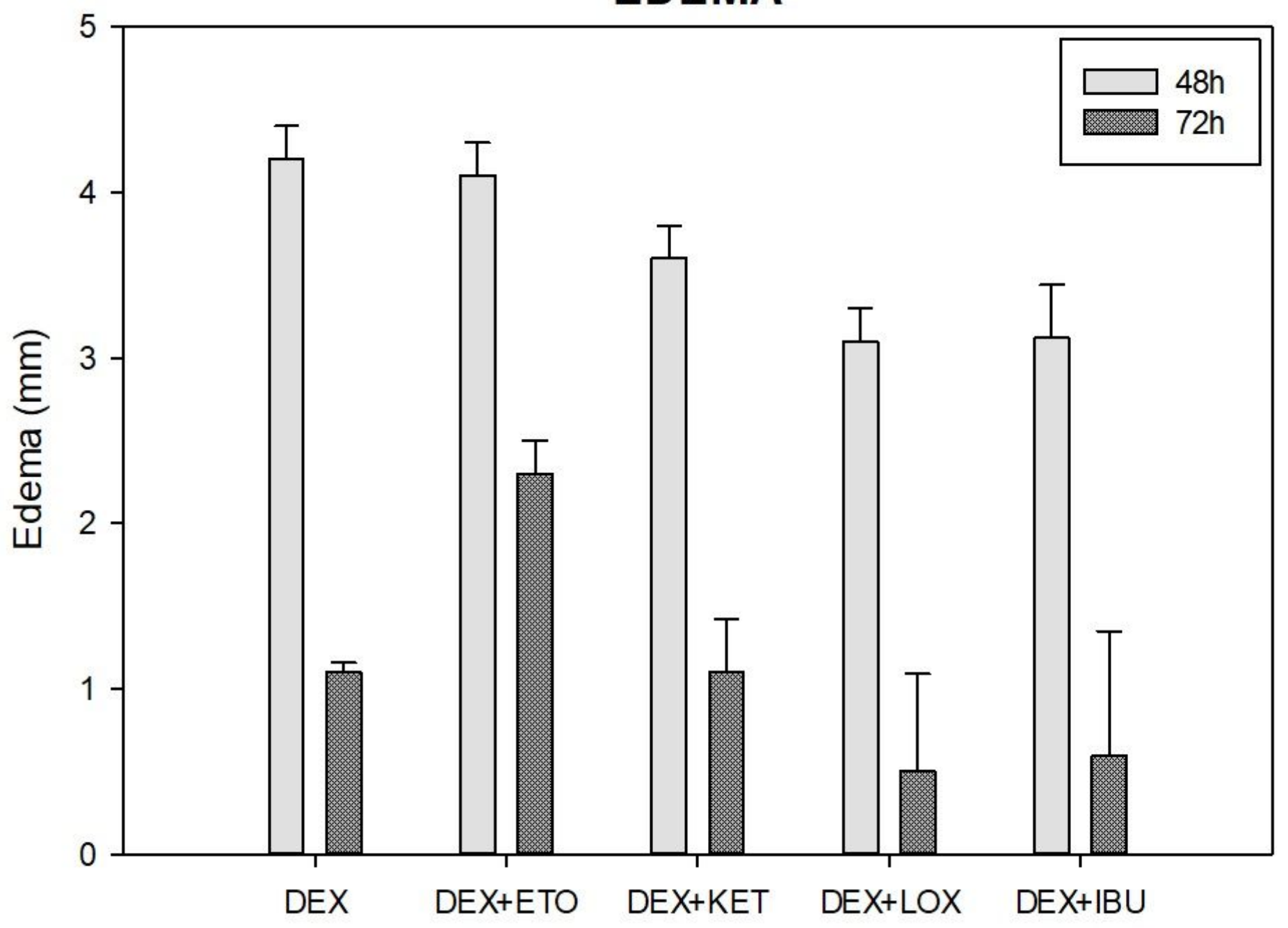

Figure 6

Chart regarding postoperative edema $(\mathrm{mm})$. Data showed no significant difference between groups in both periods. 


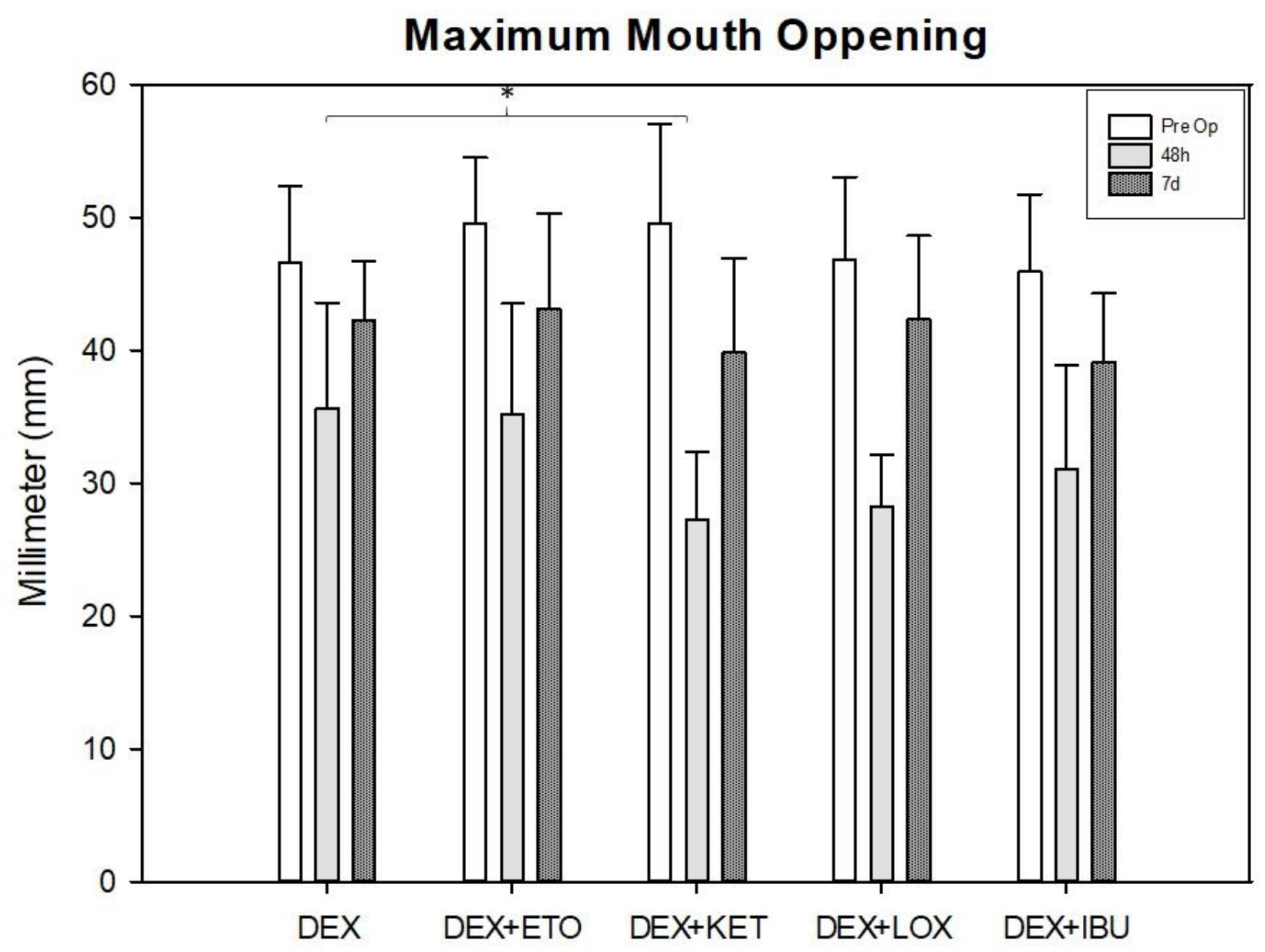

Figure 7

Chart regarding maximum mouth opening $(\mathrm{mm})$. It was observed that DEX+KET group showed significant lower MMO at 48 hours postoperative compared to DEX group ( $P<0.05-$ Tukey test). Other groups showed no significant difference on postoperative MMO. 